\title{
A INTERDISCIPLINARIDADE NO DIAGNÓSTICO DE CARCINOMA EPIDERMÓIDE
}

\section{INTERDISCIPLINARITY IN THE DIAGNOSIS OF SQUAMOUS CELL CARCINOMA}

\author{
Dulce Helena Cabelho Passarelli* \\ Sandra Ribeiro Gobbo* \\ Mackenna Campos** \\ Pâmela Cristina de Oliveira***
}

\begin{abstract}
RESUMO
O exame clínico criterioso é um método eficaz na busca de alterações importantes que conduzem a um diagnóstico preciso de lesões bucais. Somados a este, exames complementares deverão ser solicitados para elucidar e definir o diagnóstico. O Cirurgião-dentista tem importância na verificação de alterações bucais, bem como na indicação e execução desses exames. Diante disso, exames através de imagens e estudo de fragmentos colhidos por biópsia são prioridade, quando outros não foram suficientes para a precisão do diagnóstico. Este relato de caso clínico baseou-se no diagnóstico de carcinoma epidermóide em rebordo alveolar inferior, região com baixa incidência, através de imagens radiográficas e de exame histopatológico em um paciente do gênero masculino que foi encaminhado ao serviço de triagem da Clínica Odontológica da UNICID para diagnóstico de lesão em rebordo que não apresentava sinais de cicatrização após exodontia local, em um período de 60 dias, e mostra como a interdisciplinaridade atua na rapidez do diagnóstico e tratamento.
\end{abstract}

DESCRITORES: Carcinoma • Diagnóstico • Câncer bucal

\section{ABSTRACT}

The criterious clinical exam is an efficient method of searching important alterations, which leads to a sharp diagnosis of oral lesions. Added to this, complementary exams must be taken in order to elucidate and define the diagnosis. Dentists play an important role in the verification of oral alterations, as well as in the indication and execution of those exams. Therefore, exams through images and study of pieces taken during the biopsy are a priority when others were not sufficient to determine the diagnosis. This reporting of a clinical case was based on the diagnosis of squamous cell carcinoma in inferior alveolar ridge, a region of low incidence, through radiographic images and histopathologic exam of a male patient. He was transferred to the triage system of the Odontologic Clinic in UNICID to diagnose the lesion on alveolar ridge, which did not present any sign of healing after local extraction on a period of sixty days; moreover, this reporting shows how much interdisciplinarity helps to fast diagnosis and treatment.

DESCRIPTORS: Carcinoma • Diagnosis • Mouth neoplasms

* Prof ${ }^{\text {a }}$ Ms.dos Cursos de Odontologia, Biomedicina e Medicina da Universidade Cidade de São Paulo dcabelho@cidadesp.edu.br

** CD responsável pela triagem da clínica odontológica da Unicid.

*** Discentes do Curso de Odontologia Unicid. 
PASSARELLI DHC

GOBBO $S R$

CAMPOS M

OLIVEIRA PC

A INTERDISCIPLINARIDADE NO DIAGNÓSTICO DE CARCINOMA EPI-

DERMÓ I DE

REV, ODONTOL.

UNIV, C I D. SÃO

PAULO

$2011 ; 23(3)$ :

273-7, SET-DEZ

\section{N T R O D U ÇÃ O}

O Câncer Bucal, pela sua frequência, constitui-se em problema de saúde pública (INCA $\left.{ }^{1}, 2003\right)$. A Organização Mundial de Saúde (OMS) refere 640.000 casos novos de câncer de boca por ano. As neoplasias malignas da boca constituem $4 \%$ de todas, ocupando o $8^{\circ}$ lugar entre os homens e o $11^{\circ}$ entre as mulheres, sendo que a incidência mundial é 7,9: 100.000 entre os homens e 2,3: 100.000 entre as mulheres (Kowalski e Nishimoto ${ }^{2}$, 2000). O câncer bucal está relacionado a fatores de risco conhecidos como etilismo e tabagismo, $\left(\mathrm{INCA}^{3}, 2002\right)$, pois apresentam sinergismo e são promotores e iniciadores da carcinogênese, ao lado de causas coadjuvantes (má higiene, próteses mal adaptadas, imunossupressão, infecções virais pelo papiloma e herpes-vírus I e deficiências nutricionais) (Regezi $\left.{ }^{4}, 1991\right)$. Quanto ao prognóstico, variáveis como idade, histopatologia, estadiamento e região anatômica são determinantes da evolução nesses pacientes, em sua maioria do gênero masculino, após a quinta década de vida (Parise 5, 2000). Assim, reconhecido o predomínio do carcinoma epidermóide da boca, o perfil epidemiológico deve ser estabelecido para a avaliação da situação atual e para a indicação de propostas adequadas, visando à sugestão de programas de prevenção e de detecção precoce dessas neoplasias malignas (Loffredo et al. $\left.{ }^{6}, 2006\right)$.

Em casos de diagnóstico positivo, o tratamento traz limitações na alimentação e na comunicação, assim como, muitas vezes, limitações estéticas, podendo o paciente estar emocionalmente alterado e com sua qualidade de vida diminuída, devendo, portanto, o clínico geral e/ou especialista ficarem atentos a essas situações (Schütz ${ }^{7}$, 1997). O cirurgião-dentista tem que estar apto para investigar possíveis alterações bucais e relacioná-las com gênero, idade, etnia, hábitos e vícios, bem como caracterizações clínicas, para que o diagnóstico e o tratamento sejam instituídos a tempo.

O despreparo e a negligência dos profissionais, somados à pouca cultura da população, em relação à saúde geral e bucal, desencadeiam um problema por parte dos serviços públicos e particulares em tratar pacientes com diagnósticos tardios de lesões malignas, agravando o prognóstico e a sobrevida dos mesmos. (Neville $\left.{ }^{8}, 1998\right)$.

\section{DESCRIÇÃO DO CASO}

Paciente V. A. com 43 anos, gênero masculino, leucoderma, feirante, compareceu ao serviço de triagem e urgência da Universidade Cidade de São Paulo com queixa de "buraco na boca há 02 meses", que teve início após exodontias em dentes anteriores inferiores. À inspeção e breve colheita de sintomas pelo CD clínico geral da triagem, o paciente foi encaminhado à Clínica Cirúrgica que, pelo novo modelo curricular, alia-se à especialidade Estomatologia. Submeteu-se ao exame clínico que faz parte do protocolo de atendimento. À anamnese, relatou não ser portador de doença sistêmica e que não fazia uso de medicação alguma. Tabagista crônico (30 cigarros por dia), negou etilismo. No exame físico intrabucal, notou-se úlcera medindo mais ou menos $04 \mathrm{~cm}$, com exposição óssea, em região anterior de rebordo alveolar inferior, lado esquerdo, com áreas necróticas na periferia da lesão. Sangrante ao menor toque e indolor em toda sua extensão. À curetagem na região

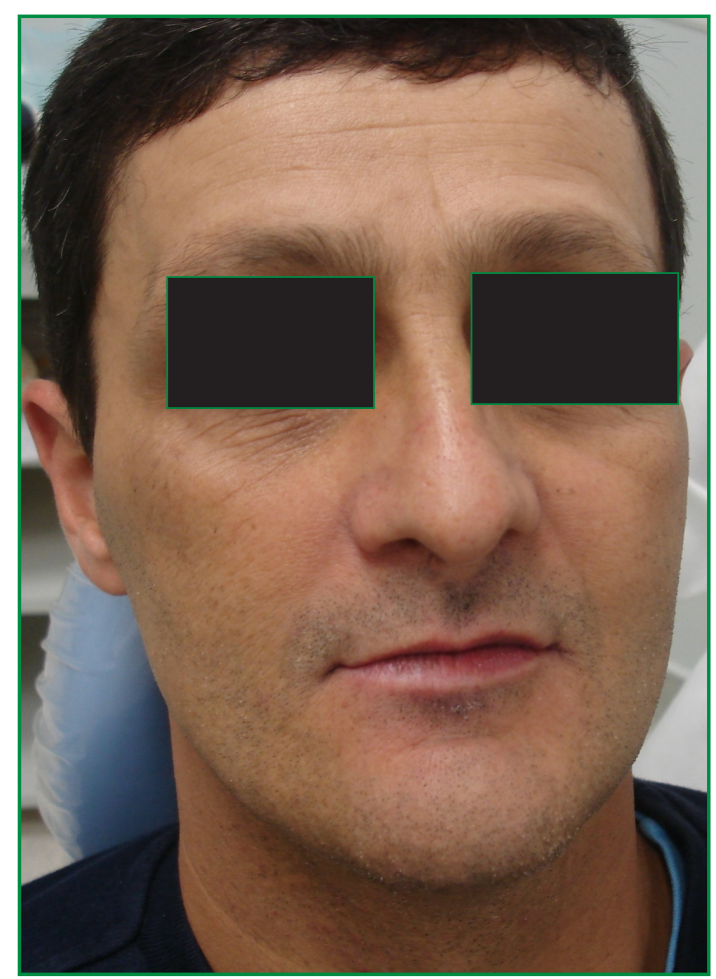

Figura 1 - Exame Extrabucal 


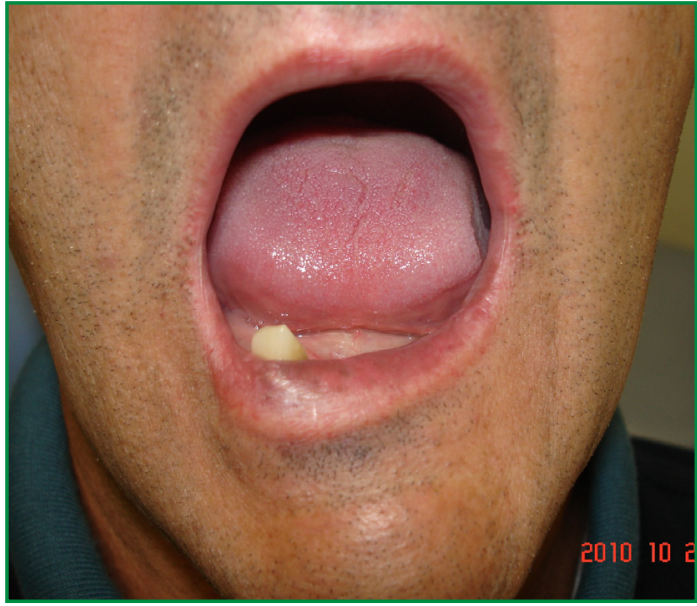

Figura 2 - Notar ligeiro desvio de abertura bucal correspondente ao lado da lesão

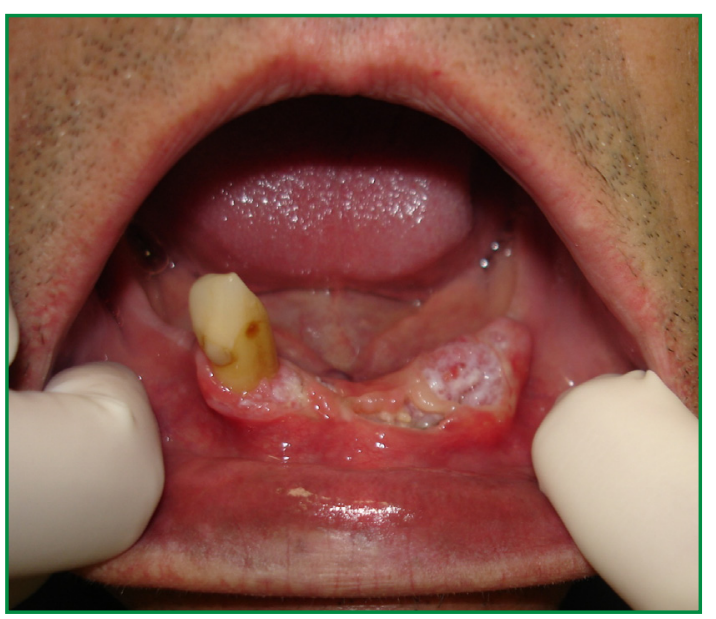

Figura 3 - Exame Intrabucal.úlcera crateriforme em rebordo alveolar inferior do lado esquerdo.

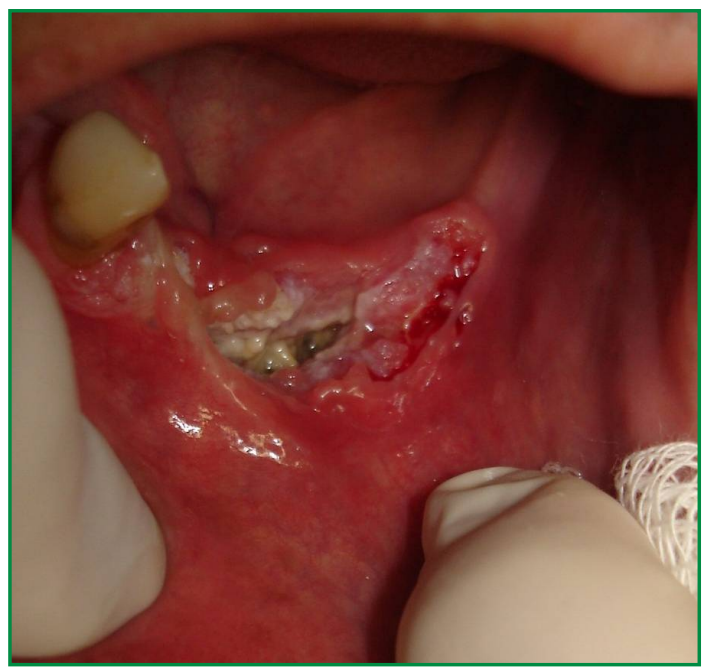

Figura 4 - Áreas sangrante ao toque com exposição óssea e perda de tecido de sustentação.

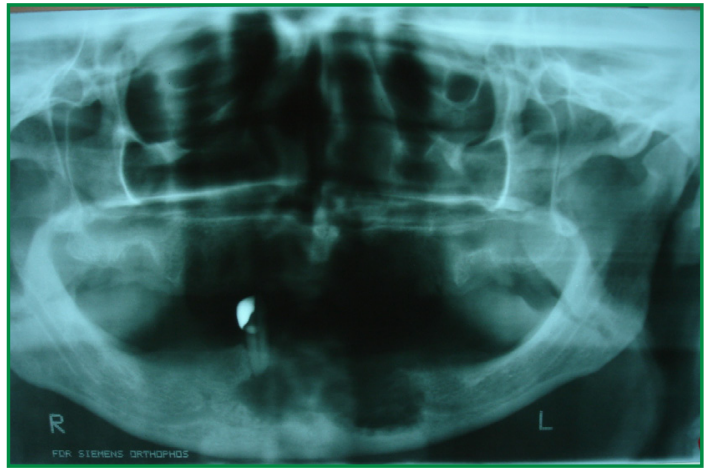

Figura 5 - Imagem radiolúcida em região de corpo de mandíbula do lado esquerdo circundada por halo radiopaco irregular.

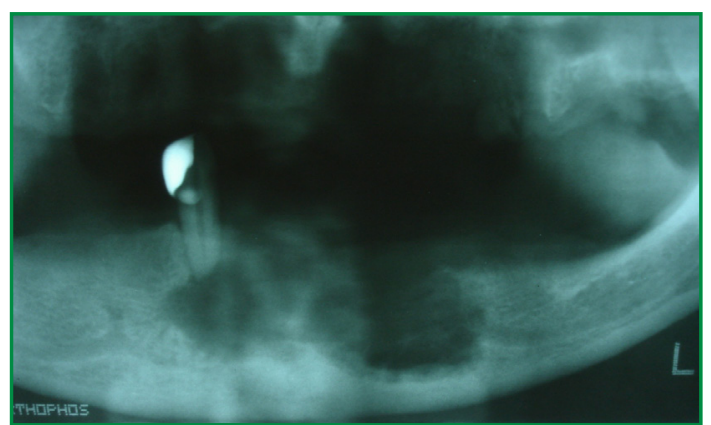

Figura 6 - Vista ampliada da radiografia panorâmica com visualização da área envolvida

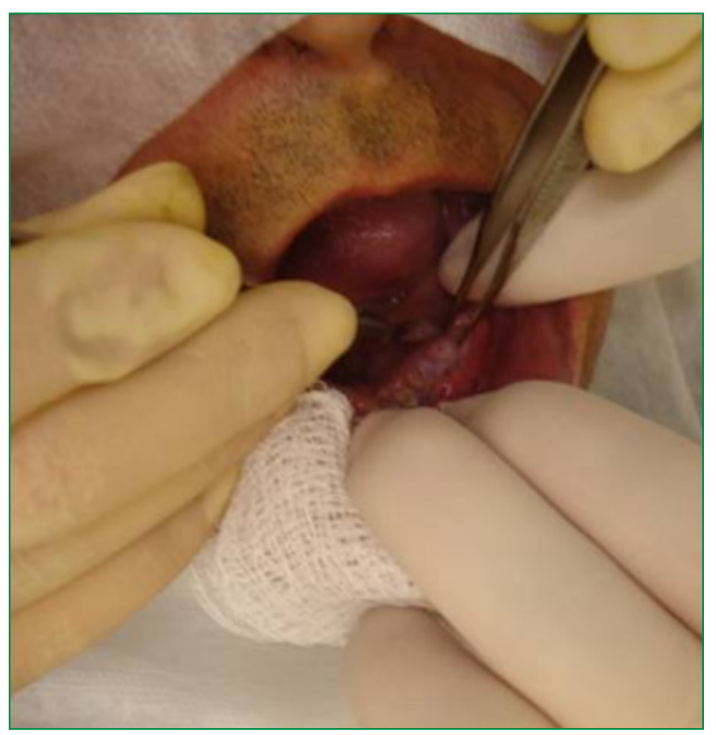

Figura 7 - Biópsia de fragmento da lesão para exame anátomo -patológico

central, notava-se perda importante de tecido de sustentação e colheita de tecido friável. Foi solicitada radiografia panorâmica, que revelou área radiolúcida na região anterior de mandíbula circundada por halo radiopaco irregular. Em seguida, foi submetido à biópsia e ao exame ana-
PASSARELLI DHC GOBBOSR

CAMPOS M

OLIVEIRA PC

A INTERDISCI PLINARIDADE NO DIAGNóstICO DE CARCINOMA EPIDERMÓ I DE

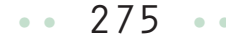

REV, ODONTOL. UnIV. CID. São PAULO 2011; 23(3): $273-7$, SET-DEZ 


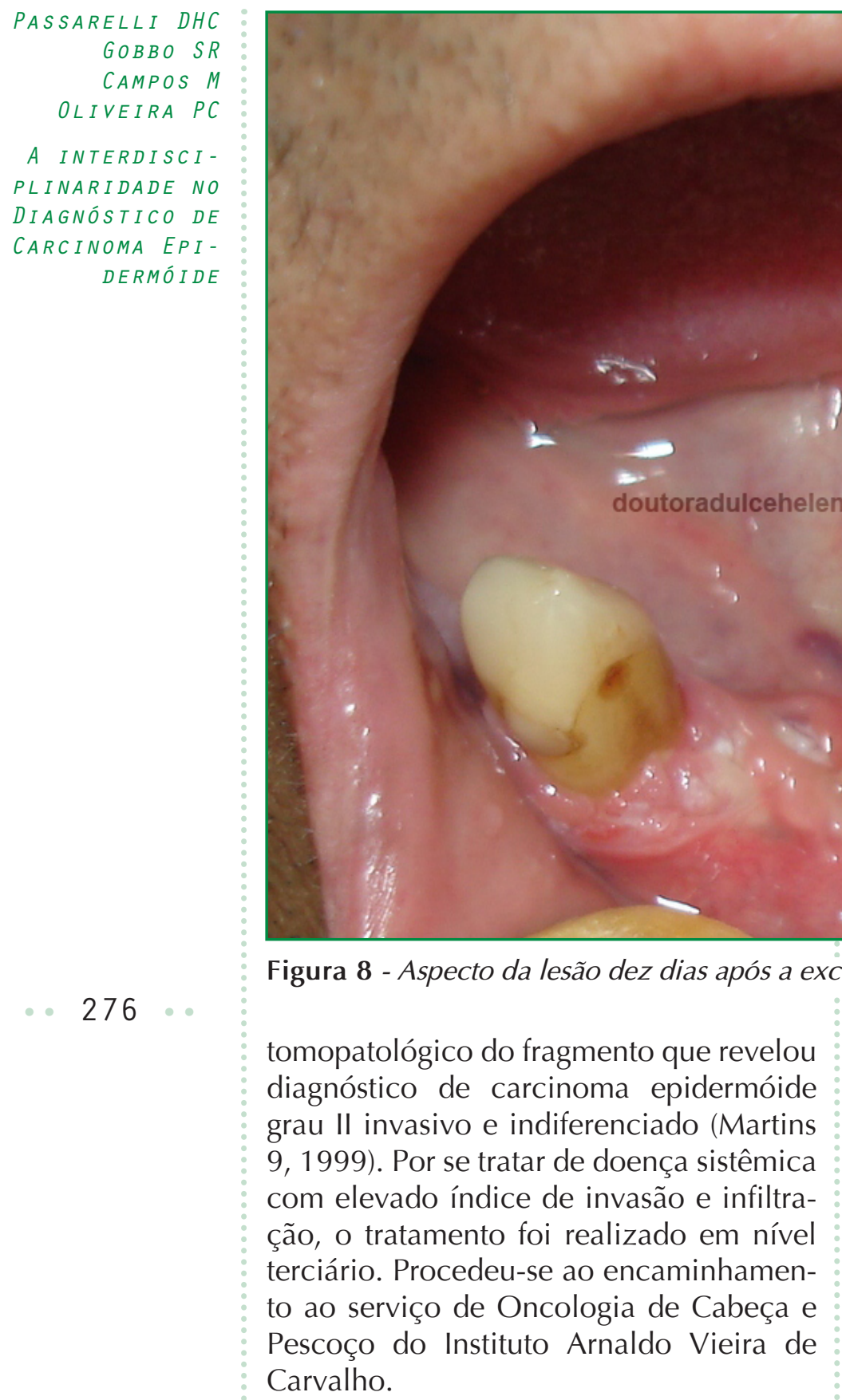

\section{I S CUSSÃO}

- A importância desse caso clínico está relacionada à interdisciplinaridade que deve existir dentro das atividades clínicas na formação do cirurgião-dentista. Os pacientes são encaminhados para o setor de triagem e direcionados às clínicas para que sejam atendidos e recebam o diagnóstico e tratamento adequados. Neste caso, além do setor de triagem, o paciente foi encaminhado para a clínica cirúrgica que envolve a Estomatologia. Dessa forma, os discentes têm a oportunidade de examinar e relacionar os conteúdos teóricos aos sinais clínicos de alterações bucais malignas. São orientados na execução de biópsia e exame anatomopatológico, bem como no encaminhamento para tratamento.

- Outro ponto importante a ser discutido refere-se à epidemiologia desse carcinoma que tem a língua e o lábio como as regiões anatômicas mais frequentes e sua ocorrência em rebordo é menos frequente (INCA 10, 2004) (Lopes et al. ${ }^{11}, 2001$ ).

- A faixa etária do paciente tem variação da $5^{\mathrm{a}}$ ou $6^{\mathrm{a}}$ década de vida, pela literatura (INCA ${ }^{12}, 2001$, Boing et al. $\left.{ }^{13}, 2006\right)$.

- O exame clínico coerente e completo, pautado em base científica e clínica, torna o cirurgião-dentista um profissional completo, dentro da proposta de interdisciplinaridade que os novos modelos curriculares almejam.

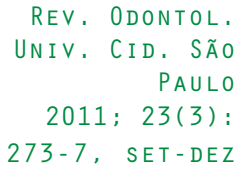


PASSARELLI DHC

GOBBO $S R$

CAMPOS M

OLIVEIRA PC

A INTERDISCIPLINARIDADE NO

DIAGNÓSTICO DE CARCINOMA EPIDERMÓ I DE

4. Regezi JA. Patologia bucal: correlações clinicopatológicas. Rio de Janeiro: Guanabara Koogan; 1991.

5. Parise O. Câncer de boca: aspectos básicos e terapêuticos. São Paulo: Sarvier; 2000.

6. Loffredo L, Pinelli C, Vitussi T, Sundefeld M, Campos J. Oral cancer mortality trends in Brazilian geographical regions from 1996-2001. Rev CiêncFarm Bás Apl 2006 27(2):133-8.

7. Schütz A. Carcinoma epidermóide bucal: aspectos microscópicos e comportamento biológico RGO 1997 mar.-abr.;45(2):1-9.

8. Neville B. Patologia oral \& maxilofacial. Rio de Janeiro Guanabara Koogan; 1998.

9. Martins MN. Sistemas de graduação histopatológica de malignidade (SGHM) do carcinoma espinocelular. revisão da literatura e sua importância dentro do contexto da estomatologia. Rev Odonto Ciênc 1999 dez.;14(28):97-106.

10. INCA BMdSSdVeSSdAàSINdC-. Estimativa 2005: incidência de câncer no Brasil. Rio de Janeiro: INCA; 2004. Available from: http://bvsms.saude.gov.br/bvs/publicacoes/ estimativa_versaofinal.pdf.

11. Lopes F, Cutrin M, Silva M. Contribuição ao estudo epidemiológico do câncer bucal. Rev Inst Ciênc Saúde 2001 jan-jun.;19(1):51-6.

12. INCA INdC. Carcinoma epidermóide da cabeça e pescoço. Revista Brasileira de Cancerologia 2001 47(4):361-76.

13. Boing AF, Peres MA, Antunes JL. Mortality from oral and pharyngeal cancer in Brazil: trends and regional patterns, 1979-2002. Rev Panam Salud Publica 2006 Jul;20(1):1-8.

Recebido em: 16/06/2011

Aceito em: 15/09/2011

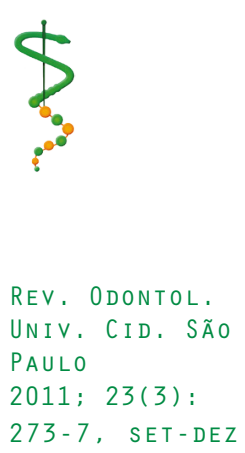

